$\begin{gathered}\text { Revista do Departamento de Geografia } \\ \text { Universidade de São Paulo } \\ \text { www.revistas.usp.br/rdg }\end{gathered}$
Volume Especial - XVII SBGFA / I CNGF (2017)
ISSN 2236-2878

\title{
A Paisagem na Geografia Física Integrada: Impressões Iniciais Sobre sua Pesquisa no Brasil entre 2006 e 2016
}

\section{Landscape in Integrated Physical Geography: Initial Impressions on its Research in Brazil Between 2006 and 2016}

\author{
Carlos Eduardo das Neves \\ Universidade Estadual Paulista (UNESP), Campus de Presidente Prudente \\ eduneves_uel@hotmail.com
}

Eduardo Salinas

Universidad de La Havana (Cuba) esalinasc@yahoo.com

Resumo: Discute-se de forma contundente nesse século XXI as trajetórias e tendências da Geografia Física Integradora ou Complexa, possibilitando uma avaliação do seu potencial ao estudo de diversas temáticas, com destaque à fragmentação, qualidade e transformação da paisagem, que encontra-se potencialmente degradada pela apropriação inadequada dos recursos e da relação contraditória entre sociedade $\leftrightarrow$ natureza. Assim, realizase um estudo bibliométrico para reconhecer um primeiro panorama dessa pesquisa desenvolvida pela Geografia brasileira, entre 2006 e 2016, permitindo pensar as trajetórias e tendências do conceito de paisagem. Para isso, coletou-se a produção sobre a temática publicada em 23 periódicos nacionais, os quais foram recuperados de acordo com o estrato do Qualis Capes Periódicos. Buscou-se entender a relevância da paisagem e do seu uso de forma integradora, bem como suas escalas e unidades de análise. Demonstra-se, ainda, a sua relação com o geossistema, entendido como conceito integrador da relação sociedade $\leftrightarrow$ natureza. A partir dos resultados, frisa-se o uso da paisagem predominantemente ligado às pesquisas ambientais, com forte vínculo à escala local, à bacia hidrográfica e à cartografia de distintos complexos paisagísticos. Avista-se, também, a importância da relação entre a paisagem e o geossistema enquanto subsídio ao diagnóstico e prognóstico ambiental. Portanto, o estudo proposto permite uma análise crítica da prática investigativa geográfica, auxiliando na valorização da geodiversidade e do patrimônio natural brasileiro, pois visualiza-se a sociedade $\leftrightarrow$ natureza enquanto um par dialético.

Palavras chave: Ambiente; Sociedade $\leftrightarrow$ Natureza, Bacia Hidrográfica, Geossistema, Escala Local.
Abstract: In this 21st century, the trajectories and tendencies of Integrated or Complex Physical Geography have been hotly discussed, which allows evaluating its potential for the study of various themes with emphasis on the fragmentation, quality and transformation of landscape, which has been potentially degraded by the misuse of resources and the contradictory relationship society $\leftrightarrow$ nature. In this regard, this paper conducts a bibliometric study for a first reconnaissance of the research in Brazil between 2006 and 2016 with a view to reflecting on the trajectories and tendencies of the concept of landscape. For this purpose, publications on the theme in 23 national journals were collected, retrieved according to the Qualis Capes classification, the Brazilian journal ranking system. The study aimed at understanding the relevance of landscape and its use in an integrated way, as well as its scales and units of analysis. It also demonstrates its relationship with geosystem, understood as an integrating concept of the relationship society $\leftrightarrow$ nature. In view of the results, emphasis is given on the use of the predominant landscape related to environmental research, with a strong link to the local scale, the watershed and the cartography of different landscape complexes. Additionally, the paper discusses the importance of the relationship between landscape and geosystem as a support for environmental diagnosis and prognosis. Therefore, a critical analysis of the geographical investigation practice is carried out, assisting in the appreciation of geodiversity and the Brazilian natural heritage, since society $\leftrightarrow$ nature is seen as a dialectical pair.

Keywords: Environment; Society $\leftrightarrow$ Nature, Watershed, Geosystem, Local Scale. 


\section{INTRODUÇÃO}

Discutir a aplicação do conceito de paisagem na Geografia Física possibilita vislumbrá-lo a partir de novos significados, bem como reafirmar seu potencial ao debate da relação indissociável e dialética da sociedade $\leftrightarrow$ natureza enquanto eixo epistemológico dessa ciência. Possibilita-se, ainda, pensar e avaliar a prática analítica geográfica, discutindo novas interpretações sobre o conceito de paisagem.

Dessa forma, objetiva-se discutir a importância da paisagem ao estudo da Geografia Física Integradora ou Complexa no Brasil. Para isso, analisa-se a contribuição ciêntifica publicada na última década em 23 periódicos da Geografia, permitindo pensar seu uso em um novo século de crescente mudança dos padrões ambientais globais e de intensa degradação do ambiente e do próprio homem.

Nesse intento, pergunta-se inicialmente: a paisagem apresenta fundamental apoio à Geografia Física Integrada no Brasil? As pesquisas paisagísticas possibilitam a correlação e a diversificação das escalas trabalhadas na Geografia? Como e por que o estudo da dinâmica do uso e cobertura da terra e as transformações da paisagem são temas tão representativos e recorrentes? O uso do geossistema tem sido frequentemente relacionado aos estudos que possuem a paisagem como objeto central? Pode a concepção sistêmica e holística da paisagem contribuir na planificação e gestão ambiental e territorial, convertendo-se, assim, em um fundamento espacial do paradigma ambiental neste século XXI?

Em relação aos temas representativos, aponta-se a diferenciação entre integração e compartimentação; as escalas de uso da paisagem, enfocando no uso da escala local; as unidades de análise da pesquisa paisagística, com enfoque na bacia hidrográfica. Dessa forma, pode-se enfocar na importância do geossistema e no seu potencial teórico-metodológico na integração sociedade $\leftrightarrow$ natureza.

\section{Estudos paisagísticos no Brasil: introdução para um debate de integração sociedade $\leftrightarrow$ natureza}

As investigações acerca da paisagem, com enfoque integrado, apresentam uma complexa e longa história. Assim, o conceito de paisagem se manifesta como polissêmico e resultado de uma representação filosófica e social, onde cada sociedade, por meio de sua cultura, imprime uma particular plasticidade à natureza que é produzida pela intencionalidade social (VITTE, 2007). Portanto, a paisagem é uma representação de um período histórico (herança) (AB'SABER, 2003), sendo importante compreender suas múltiplas facetas, reestabelecendo a relação entre o espaço e a sociedade que nele habita, por isso, para Passos (2013) a paisagem é uma noção.

Todavia, o presente estudo concentra-se, por ora, nas investigações da paisagem como objeto integrador da Geografia Física no Brasil. Indica-se que o debate sobre o assunto por autores brasileiros tenha se iniciado com Ab'Saber (1969), sendo aprofundada nos anos setenta e oitenta por Christofoletti (1979), Troppmair (1983) e Monteiro (1982), concentrados na geomorfologia, biogeografia e climatologia/fisiologia da paisagem, respectivamente. Tais autores sistematizaram as bases do estudo físico-geográfico complexo a partir e muitas vezes além dos pressupostos defendidos por autores como Bertrand (1968), Troll (1971), Tricart (1982) e Sochava (1978). Ao seguir essa tradição teórico-metodológica, em 1968, o Professor Ab'Saber introduz no currículo da geografia "uspiana" a disciplina de "Fisiologia da Paisagem".

Após a primeira metade da década de 1990, produziu-se uma série de trabalhos, bem como dissertações e teses que, junto à chegada de geógrafos europeus e latino-americanos, impulsionaram os estudos e temáticas relacionadas à paisagem. São importantes a esta indagação os trabalhos realizados por Ross (1995), Nucci (1998), Monteiro (2000), Cavalheiro et al. (2003) e Passos (2003) para uma análise mais ampla e integrada sobre a paisagem, especialmente voltada à perspectiva sistêmica. Entre os estrangeiros, destaca-se o cubano Mateo Rodriguez, que influenciou diversas pesquisas, especialmente na UNESP (Rio Claro e Presidente Prudente) e na UFC (Fortaleza) a partir da geoecologia da paisagem.

A realização, em diversas escalas e partes do Brasil, do Zoneamento Ecológico-Econômico (ZEE) como instrumento da Política Nacional do Meio Ambiental (decreto 4.297/2002) (BRASIL, 2002) representa, também, um ganho importante ao estudo integrador e paisagístico na Geografia por permitir que os produtos gerados sejam profícuos instrumentos de planejamento ambiental, paisagístico e territorial.

Destacam-se as pesquisas de Martinelli (1994) e Martinelli e Pedrotti (2001) acerca da cartografia ambiental enquanto instrumento teórico-metodológico para o estudo de unidades de paisagem. Para esta análise, expõe-se a integração de diversos fatores, como história geológica, morfogênese do relevo e solo, dinâmica climática e biológica e a produção social do espaço em seu processo histórico. Assim, trabalhar com unidade de paisagem permite a visualização desta como totalidade integrada. 
Com o crescimento contínuo da relação desse conceito e do uso das ferramentas de sensoriamento remoto e geoprocessamento para a avaliação de unidades paisagísticas, em pequenas e grandes áreas, nota-se o crescimento de pesquisas relacionadas ao uso da terra, qualidade, estado e conservação da paisagem aplicado à gestão e planejamento ambiental, bem como pesquisas de outras disciplinas, como Ecologia, Arquitetura e Antropologia (SALINAS E REMOND, 2015).

Portanto, o uso do conceito de paisagem tem sido aplicado de forma constante na Geografia, o qual, segundo Ortigoza et al. (2011), apresentou entre 1992 e 2008 um nítido processo de consolidação. Nesse âmbito, Salinas e Remond (2015) demonstram que na atualidade há um incremento das investigações sobre a paisagem, com destaque ao nível regional e local, onde não se enfoca apenas nas dinâmicas da natureza em seu sentido biofísico, mas também no contato com a apropriação da natureza pelas práticas sociais de produção espacial.

\section{MATERIAIS E MÉTODOS}

Por meio da ferramenta de busca de 23 periódicos indexados no Qualis Capes da Geografia, avaliação 2015, referente à classificação A1, A2 e B1, recuperou-se via download cerca de 1000 artigos que utilizaram o conceito paisagem, entre 2006 e 2016, seja como objeto central ou secundário. A opção por esse período temporal se deu em função de sua relevância às reflexões propostas, uma vez que permite a coleta online de periódicos representativos e de importância à geografia nacional, os quais anteriormente eram produzidos somente de modo impresso, além de indicar uma década de produção.

A escolha dos periódicos como material de análise se mostra eficiente ao reconhecimento da temática. Segundo Doyle e Julian (2005), são eles os principais veículos de divulgação científica e agregam diversas perspectivas analíticas, permitindo pensar as tendências quali-quantitativas da ciência.

Este estudo, inicialmente, apresenta a paisagem como objeto central, diferenciando-a da sua utilização como conceito de apoio, separando tais pesquisas por ano. Isto permitiu entender qual região do país tem tido maior atratividade, possibilitando reconhecer periódicos e temáticas mais representativas. Dessa forma, visando sistematizar os passos e variáveis analíticas adotados para o desenvolvimento do artigo, são indicados os procedimentos, representados pela Figura 1.

Assim, partir da análise bibliométrica, foi possível avaliar a produção científica acerca da Geografia Física Integrada. Esta análise tem ganhado cada vez mais espaço no ambiente acadêmico (MARANHÃO, 2014; BARRETTO et al., 2008; ALVARENGA, 1998), contribuindo ao entendimento das trajetórias e tendências do campo científico, conceito e/ou variáveis (NEVES E MACHADO, 2017).

Tais estudos subsidiam importantes reflexões epistemológicas e filosóficas sobre a prática analítica geográfica (MONTEIRO, 1980) de cunho paisagístico. No entanto, tais estudos apresentam-se pouco valorizados, notadamente, na Geografia Física (VITTE, 2008), por isso o seu potencial explicativo. 


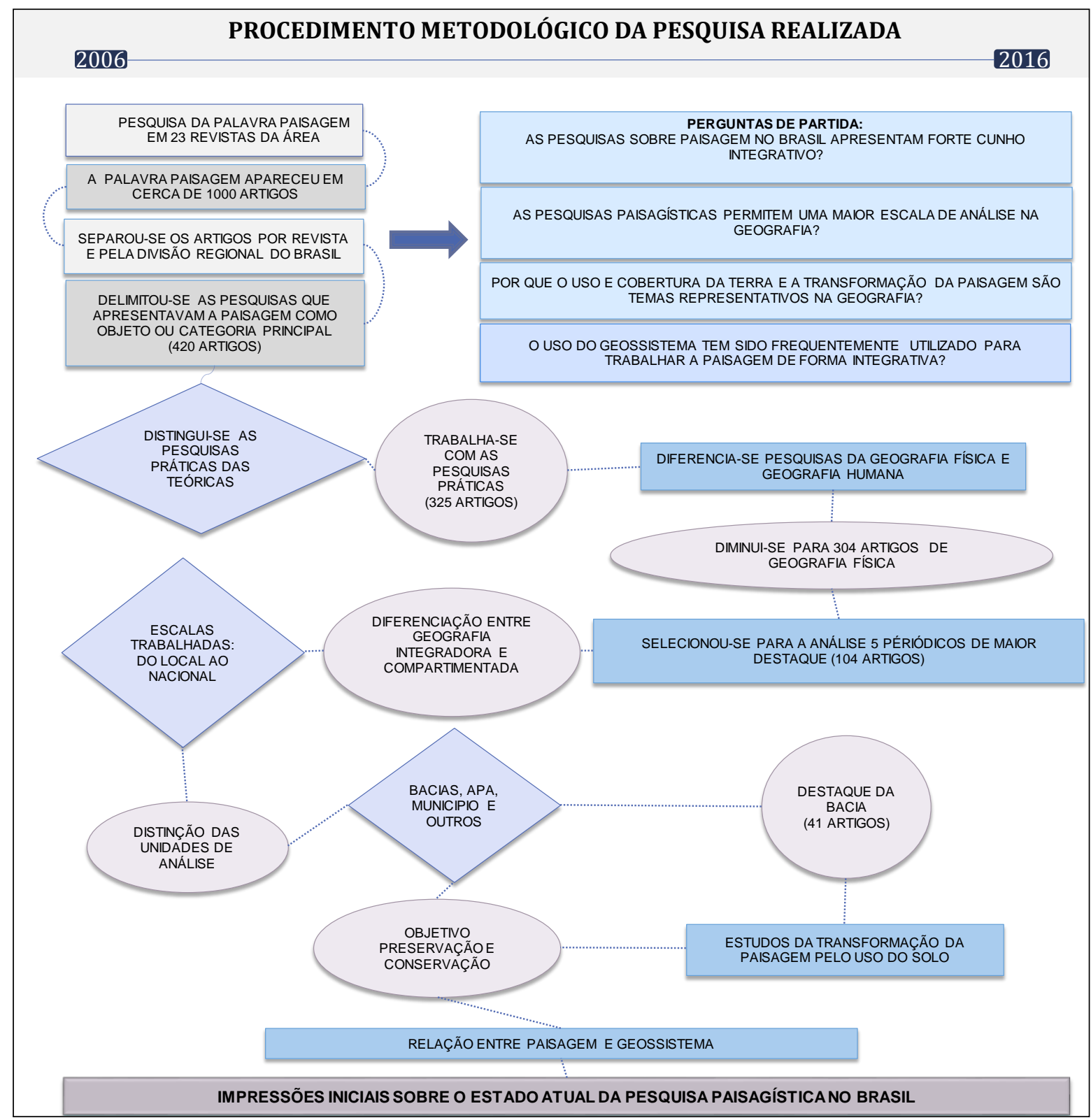

Figura 1: Fluxograma do estudo da Paisagem no Brasil, entre 2006 e 2016, a partir de periódicos.

Fonte: Autores, 2017.

\section{RESULTADOS E DISCUSSÕES}

\section{O uso do conceito de paisagem: uma análise crítica da pesquisa publicada no Brasil}

A análise realizada parte da diferenciação entre as pesquisas publicadas (2006-2016) acerca da paisagem como objeto central e secundário (Figura 2). Esse intento permitiu demonstrar que, apesar de sua relevância à Geografia, tem havido mais pesquisas que usam a paisagem de forma secundária (561 artigos) e não de forma central (422 artigos).

O conceito de paisagem como apoio aparece, em todos os estratos, de forma recorrente em $62 \%$ dos artigos no estrato A1, em $51 \%$ no estrato A2 e $57 \%$ no estrato B1. Todavia, avista-se que três periódicos contribuíram para esse resultado e com destaque as revistas bem consolidadas, as quais tiveram ou tem grande influência na produção geográfica nacional. Os periódicos são: Geografia (Rio Claro), Revista Confins, Revista do Departamento de Geografia, os quais apresentaram, respectivamente, 70\%, 75\% e 77\% de artigos utilizando a paisagem como apoio a outros conceitos e temas. 
Já a Revista Ateliê Geográfico, o Boletim Goiano de Geografia e o Espaço e Geografia (UNB) são as que mais exibem artigos que utilizam a paisagem com centralidade. Entretanto, estes tiveram pouca interferência quando comparados com os periódicos anteriormente citados. Cabe ressaltar que os principais termos para menção à paisagem enquanto conceito apoio foram: "paisagem urbana/cultural" (maior frequência na Geografia Humana) e "paisagem natural/paisagem antropizada" (maior frequência na Geografia Física).

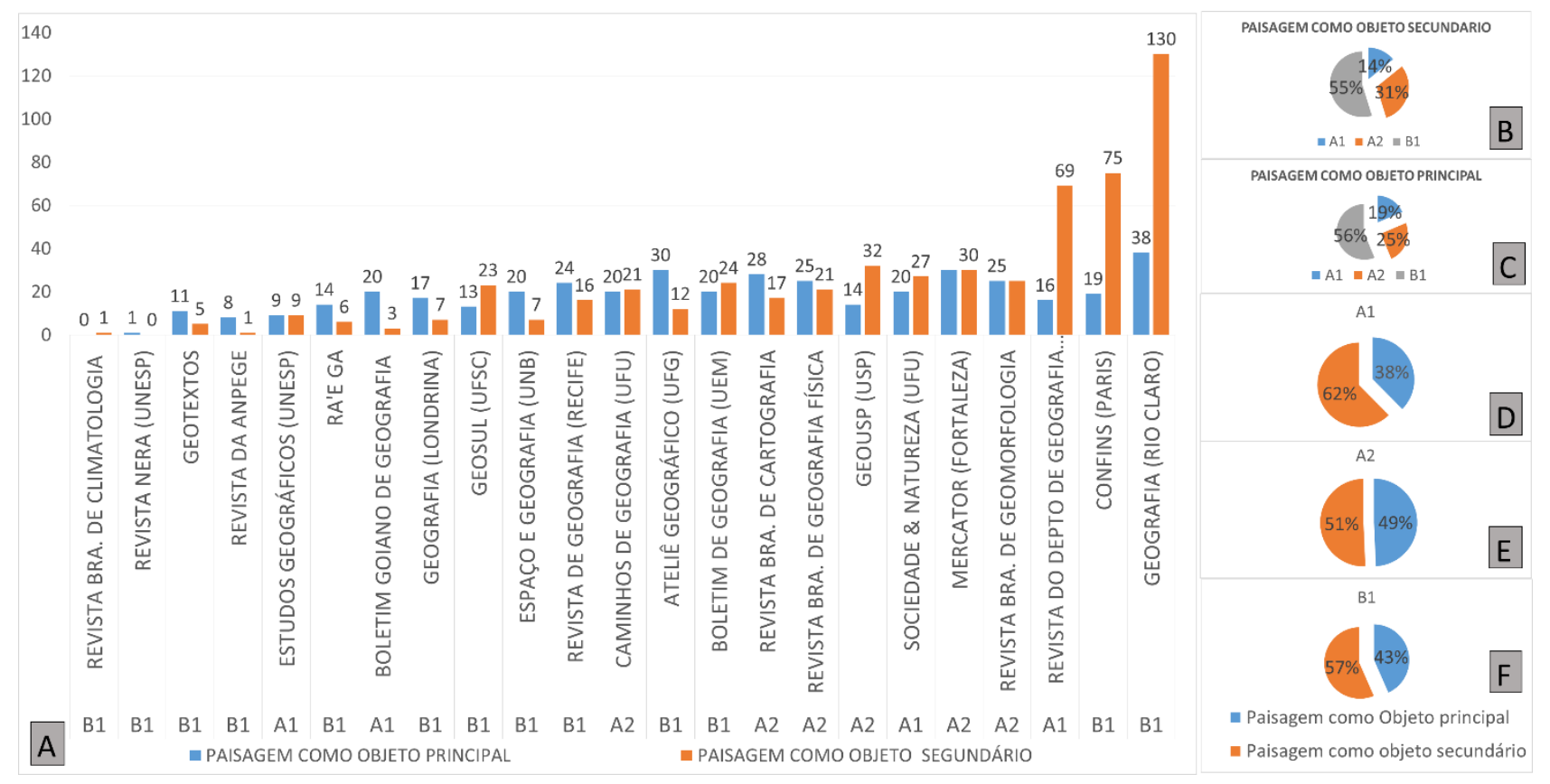

Figura 2: (A) Artigos analisados que apresentam a paisagem como objeto principal e secundário; (B) porcentagem das pesquisas com a paisagem como objeto secundário; $(\mathrm{C})$ porcentagem das pesquisas com a paisagem como objeto principal; (D) descrição dos periódicos A1; (E) descrição dos periódicos A2; (F) descrição dos periódicos B1.

Fonte: Autores, 2017.

Realiza-se uma análise temporal da amostra e contempla-se uma correlação das regiões que mais apresentam periódicos que trabalham a paisagem (Figura 3). É possível averiguar uma tendência positiva do uso desse conceito, a qual, mesmo com as oscilações, apresenta uma continuidade de aplicação em todas as regiões, com destaque à região centro oeste e região sudeste. A região norte, entretanto, é a mais oscilante, sobretudo por não apresentar poucos periódicos nos estratos analisados.

Averigua-se, entre 2006 e 2009, um menor número de artigos publicados. No ano de 2006 a região centro-oeste e nordeste apresentaram baixa produção, indicando a pequena difusão e influência que alguns periódicos tinham no cenário nacional naquela época. Hoje, tais periódicos, como a Revista Brasileira de Geografia Física, têm tido um crescimento em seu Qualis, o que tem aumentado sua atratividade.

Ao se analisar qual periódico teve mais influência em sua região, destacam-se a Revista Geografia (Recife) na região nordeste, o Boletim de Geografia (UEM) na região sul, a Sociedade \& Natureza no centro oeste e a Geografia (Rio Claro) no sudeste, sendo esta última a de maior representatividade no montante geral, com a publicação de mais de 170 artigos com o uso da paisagem. Todavia, é importante frisar que apenas as Revistas Estudos Geográficos, GEOUSP, Revista Brasileira de Cartografia e a Mercator apresentaram contribuições em todos os anos amostrados, com destaque para os anos de 2015 e 2016, havendo a publicação de 134 e 133 artigos, respectivamente. 


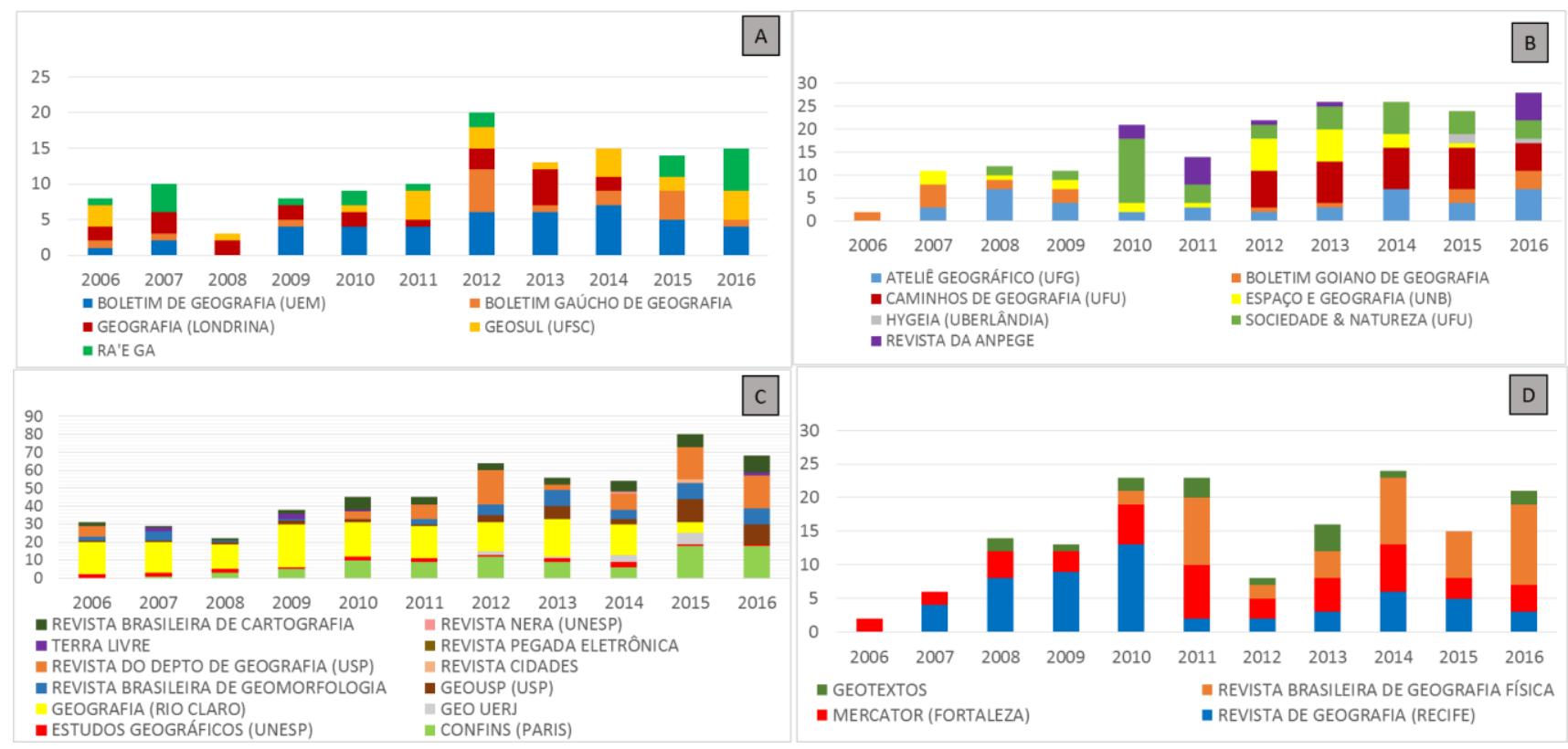

Figura 3: Artigos sobre paisagem separados por periódico, região e por ano. (A) Região Sul; (B) Região Centro-Oeste; (C) Região Sudeste; (D) Região Nordeste.

Fonte: Autores, 2017.

É possível apurar que as pesquisas relacionadas à paisagem são majoritariamente aplicadas (Figura 4), especialmente analisando a paisagem junto ao planejamento e à gestão ambiental, devido às transformações e fragmentações do ambiente e à criação de novas paisagens.

Tais pesquisas buscam gerar conhecimentos em nível de planos locais e regionais, contribuindo ao reconhecimento da estrutura funcional, da eficiência de uso segundo o grau de intensidade das ações antropogênicas, e a partir da análise e mapeamento das unidades de paisagem - importantes produtos no auxílio e manutenção da biodiversidade e geodiversidade no país.

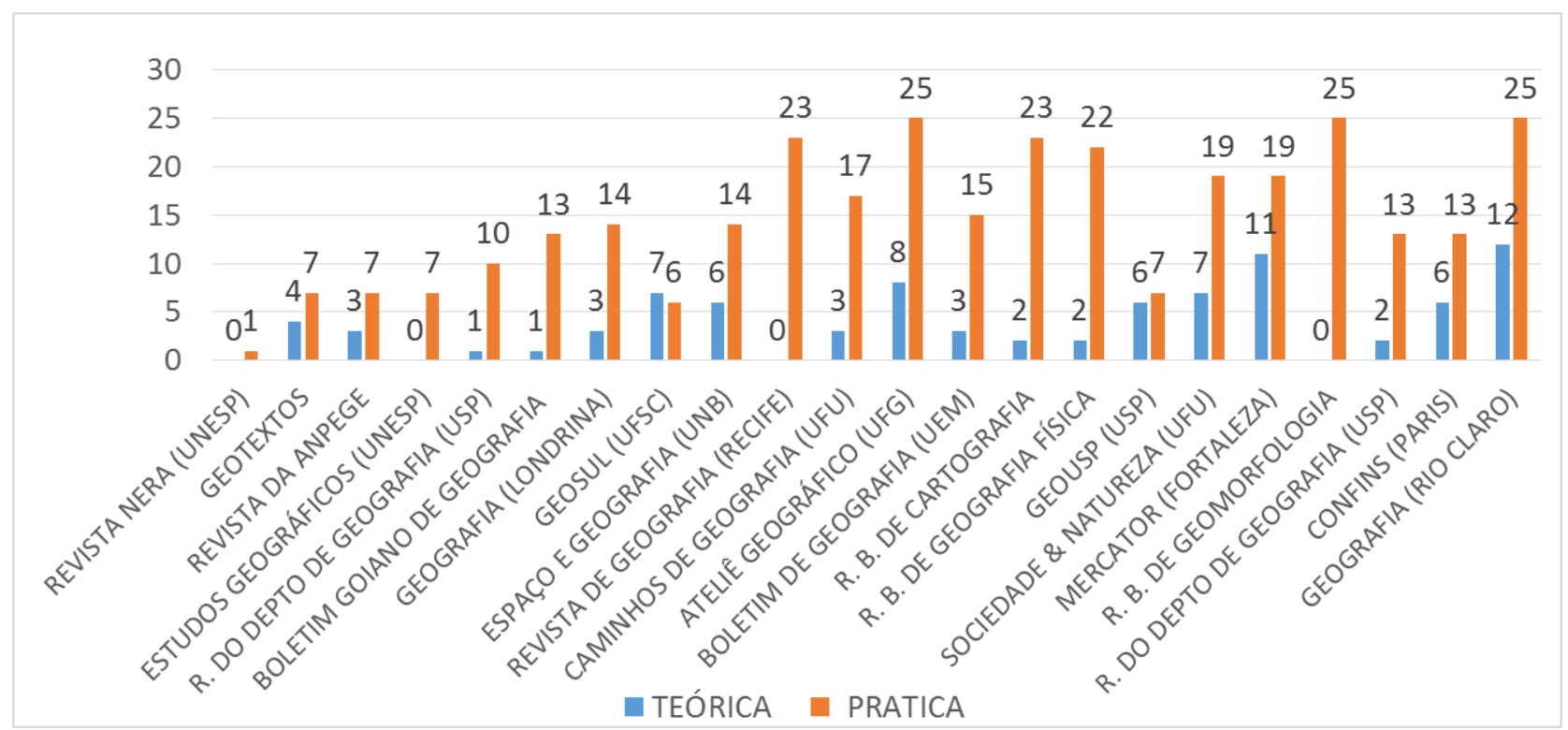

Figura 4: Pesquisas com a paisagem como objeto principal, com destaque às teóricas e as práticas.

Fonte: Autores, 2017. 
Todavia, a paisagem tem mudado de finalidade e de conteúdo, pois tem participado de maneira mais evidente da análise da cultura e do simbólico, tem assumido ainda maior relevância como um dos componentes das políticas de ordenamento - ambiental e patrimonial - dos territórios (PASSOS, 2013). Isso explica o crescente uso desse conceito na Geografia Humana.

Devido à sua versatilidade, a paisagem é empregada junto a outros conceitos, como território, lugar, região, ambiente e espaço. Entretanto, continua sendo frequentemente associada à Geografia Física, com toda sua materialidade (Figura 5).

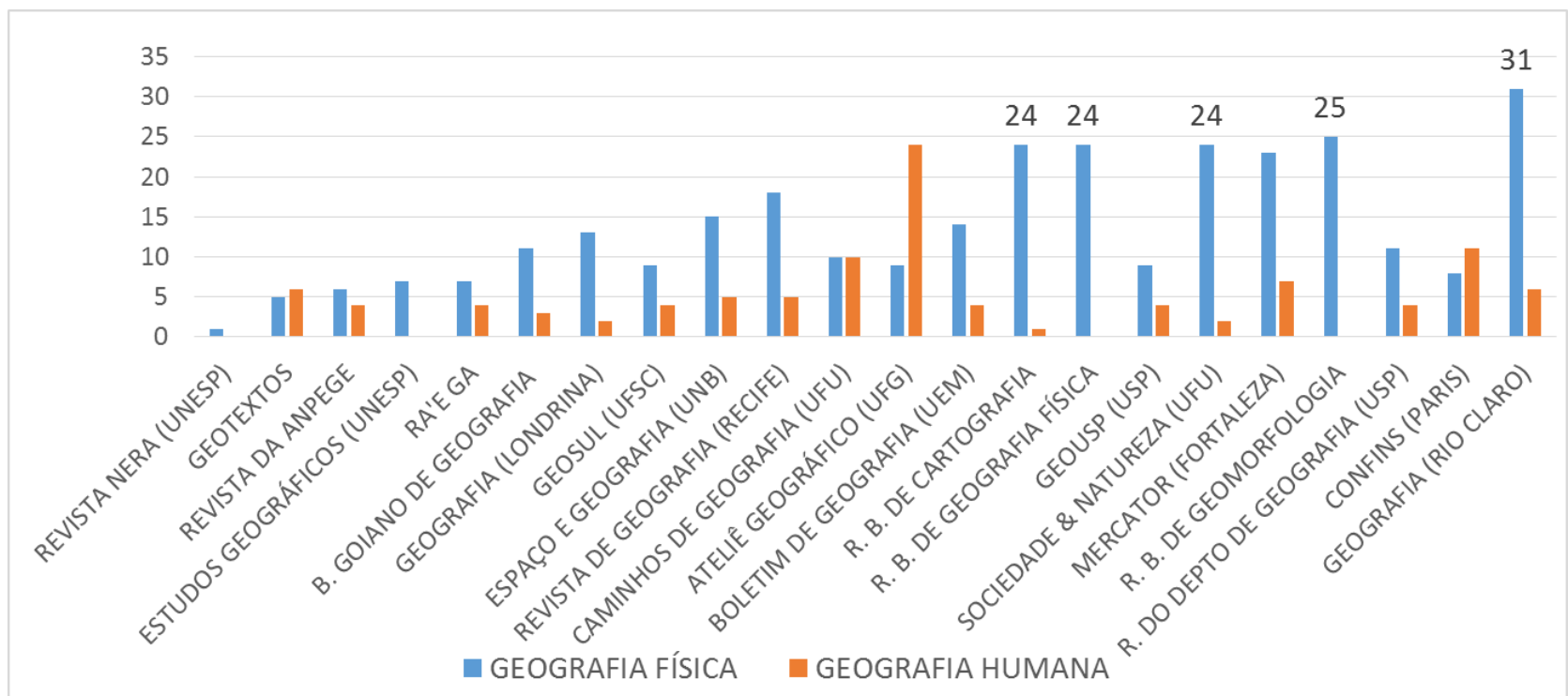

Figura 5: Área de concetração das pesquisas sobre paisagem como objeto central, com destaque aos periódicos mais representativos.

Fonte: Autores, 2017.

Ao reconhecer a importância de alguns periódicos em detrimento da amostra, destacaram-se os 5 mais relevantes (em relação à quantidade de artigos - Figura 5) voltados à análise da Geografia Física. São eles: a Revista Brasileira de Cartografia, Brasileira de Geografia Física, Sociedade \& Natureza (UFU), Revista Brasileira de Geomorfologia e Geografia (Rio Claro). Por meio dos periódicos supracitados, diferenciam-se pesquisas integradas (relação da sociedade $\leftrightarrow$ natureza) em detrimento das compartimentadas (processos naturais com ou sem a interferência social) (Figura 6).

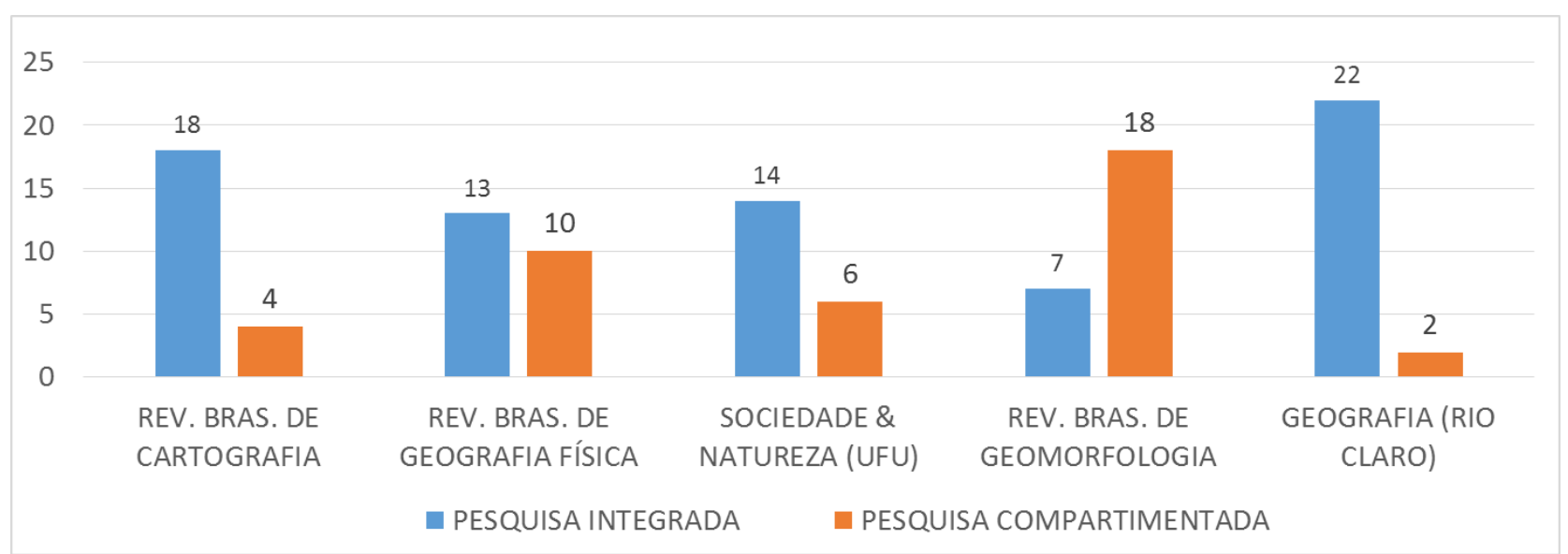

Figura 6: A paisagem integrada e compartimentada a partir dos cinco periódicos mais representativos Fonte: Autores, 2017. 
Para realizar essa diferenciação, analisaram-se os objetivos de cada artigo. A esse respeito, Suertegaray e Moretti (2014) bibliometrizaram o eixo "Natureza" no Encontro Nacional dos Geógrafos (ENG), demonstrando o seu uso integrado aos processos sociais, o que chamou de pesquisas do "Ambiente". Seguindo os mesmos parâmetros, Neves e Machado (2017) apresentam o uso do geossistema enquanto conceito importante para a integração geográfica, identificando a maior relevância dos estudos integradores.

Entretanto, nota-se a perspectiva inversa na Revista Brasileira de Geomorfologia, fato explicado por sua especialização em conteúdos geomorfológicos, especialmente o desenvolvimento de grandes conjuntos de relevo, dinâmicas fluviais, solo-vertente, erosão, ligados à recuperação de áreas degradadas, empregando novas técnicas e geotecnologias, onde a paisagem geralmente tem um carater de natural/antropizado. A revista Geografia (Rio Claro), por sua vez, é a que mais tem contribuido com a publicação de artigos que trazem a paisagem de forma integradora, pois é menos específico, especialmente pela tradição que o periódico tem em pesquisas voltadas para análises geoambientais de enfoque sistêmico-dialético. Essa tendência também é vista na revista Sociedade \& Natureza, que tem apresentado uma diversidade de pesquisas enfatizando a relação integradora. Já a Revista Brasileira de Geografia Física e a de Cartografia apresentam o uso e a corbertura da terra como principal enfoque, nas quais o uso de geotecnologia aprensenta-se como um ponto basilar.

A leitura inicial dos dados demonstra que há uma aproximação dos geógrafos que pesquisam as dinâmicas da natureza dos temas que classicamente são trabalhados por geógrafos das humanidades. Tais temáticas são, por exemplo: cultura, urbanização, resíduos, políticas públicas, conflitos sociais e populações tradicionais. Nesse âmbito, a análise do uso e cobertura da terra se deu como o principal instrumento de integração homem $\leftrightarrow$ sociedade $\leftrightarrow$ natureza.

Outro tema importante são as escalas trabalhadas pelas pesquisas paisagísticas (Figura 7a), bem como suas unidades analíticas (Figura 7b).

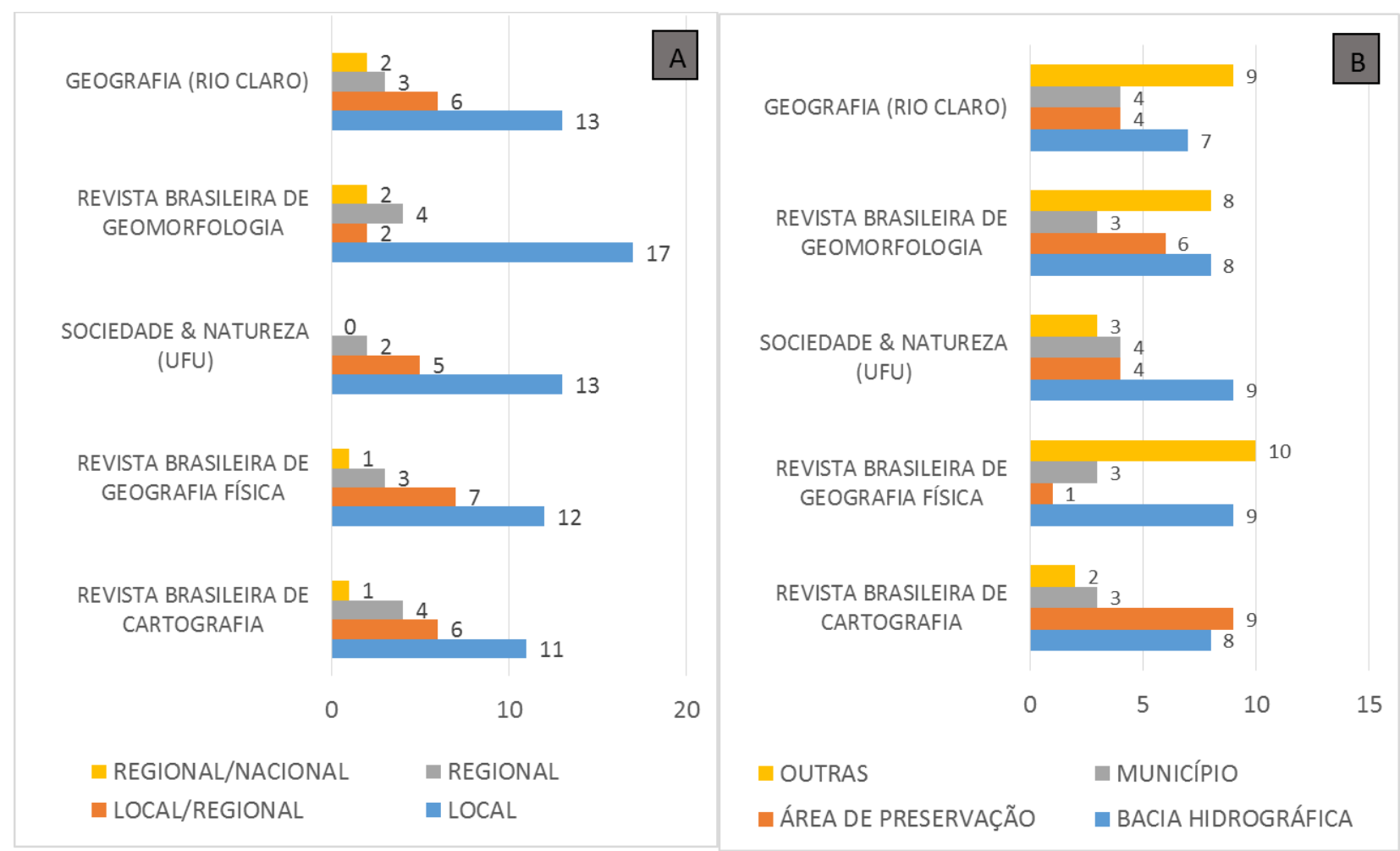

Figura 7: (A) as escalas trabalhadas junto à categoria paisagem; (B) as unidades de análise mais representativas de estudo da paisagem nos cinco periódicos mais representativos da amostra Fonte: Autores, 2017.

Ao estudar as escalas de aplicação, pode-se entender as diferentes estruturas e dinâmicas da paisagem, além das transformações causadas pelo uso da natureza socializada. Neste caso, entender as escalas que mais tem sido importante aos estudos paisagísticos possibilita demonstrar o grau da perturbação do ambiente gerada com a relação contraditória sociedade e natureza. Por isso, temas como o limiar 
homeostático, equilíbrio-desequilíbrio do sistema, risco e resiliência são, por vezes, expostos, permitindo entender os graus de impacto, especialmente por meio das unidades de paisagem.

Avista-se uma tendência de uso da escala local em todos os periódicos. Tal fato pode advir dos pressupostos epistemológicos dessa ciência, com relevância na reinvenção do "lugar", mas também da necessidade da escolha de uma melhor escala para o ordenamento físico-territorial e da possibilidade de trabalhos de campo sistemáticos com emprego de técnicas "manuais".

À luz da Figura 7 (B), mira-se que a "bacia hidrográfica" só não é mais representativa que "outros estudos", os quais agregam diversas unidades analíticas, entre elas os setores censitários, áreas marginais de rodovias, bairros, escolas, áreas urbanas, praças (locais), entre outras, como os estados, domíníos geomorfoclimáticos e biomas.

Indica-se, ainda, que ao agrupar o uso das "bacias hidrográficas" (grande maioria), das "unidades de preservação" (grande maioria) e dos "municípios" como unidades da escala local e local/regional, demonstra-se que estes indicam 80,7\% da amostra dos 5 periódicos.

Neste caso, somente a "bacia hidrográfica" representa 36\% da amostra (41 artigos), sendo a Revista Sociedade \& Natureza a mais representativa com 9 pesquisas integradas utilizando essa unidade analítica. Assim, a partir dessa unidade, é possível mensurar de forma detalhada os atributos e variáveis dos complexos paisagísticos, bem como o reconhecimento dos padrões de modificação do meio físico em distintas escalas espaço-temporais pelo processo de apropriação do espaço.

\section{A paisagem e o geossistema: caminhos iguais ou paralelos?}

É expressivo o potencial teórico-metodológico do conceito de geossistema na Geografia Física devido à necessidade de se entender as relações integradoras em seu aparato conceitual, enfocando, sobretudo, no que Cavalcanti e Corrêa (2014) chamam de "síntese naturalista". Por meio desse pressuposto, correlaciona-se o geossistema ao conceito de paisagem, considerando que o primeiro foi criado na antiga União Soviética a partir de uma longa tradição dos estudos paisagísticos e dos complexos territoriais naturais (SOCHAVA, 1978; SNYTKO E SEMENOV, 2008), bem como enquanto solução aos problemas metodológicos vivenciados pelo conceito a partir dos anos de 1950 (FROLOVA, 2006).

Assim, diante da necessidade de análise de um vasto número de dados surgidos com as estações experimentais soviéticas e dos altos impactos nas paisagens regionais, criaram-se, em consequência, teorizações e aplicações sobre a dinâmica, funcionamento e evolução do aparado teórico-metodológico geossistêmico, reconhecendo a fundo diversos complexos paisagísticos, os quais não estavam alheios aos processos e ações sociais (BERTRAND, 1968; BEROUTCHACHVILI E BERTRAND, 1978).

Ao demonstrar a diversidade temática, escalar e analítica na relação do geossistema com a paisagem, criou-se o Quadro 1 mostrando pesquisas da amostra geral que utilizaram o potencial explicativo do geossistema, ora utilizado como apoio, ora como objeto central de análise em diversas pesquisas.

Ao apresentar tal quadro, reforca-se a análise integrada trazida pelo geossistema e pelas discussões realizadas nos tópicos anteriores, bem como a versatilidade dessa relação em diversas unidades de análise e temáticas onde o debate ambiental de cunho integrado tem tido expressividade.

Finaliza-se essa breve análise realçando que a dinâmica e a relação dos elementos da paisagem estão na origem do conceito de geossistema. Por isso, presenciou-se em diversas pesquisas a utilização desse potencial teórico-metodológico, demonstrando uma diversidade de temas abordados, os quais incluem majoritariamente (a) a utilização de técnicas de sensoriamento remoto e geoprocessamento para relacionar as mudanças na paisagem, e (b) o uso e cobertura da terra no que tange a produção social do espaço. Assim, o geossistema aparece como um conceito importante ao estudo da estrutura, funcionamento, dinâmica e evolução da paisagem.

Portanto, demonstra-se que a proposta do geossistema vem substituir os estudos pautados exclusivamente na dinâmica biológica do ecossistema, por integrar de forma mais próxima os sistemas naturais e humanos, visto que sua existência se dá pela relação dialética entre distintos agentes formadores da paisagem. Ambos os conceitos, portanto, são considerados uma herança e uma totalidade sistêmica. 
Quadro 1: O geossistema em estudos paisagíticos a partir de alguns periódicos analisados.

\begin{tabular}{|c|c|c|c|c|c|c|c|}
\hline Periódicos & Autor & Ano & $\begin{array}{c}\text { Tipo } \\
\text { de } \\
\text { Estudo }\end{array}$ & $\begin{array}{l}\text { Integrado / } \\
\text { Comparti- } \\
\text { mentada }\end{array}$ & $\begin{array}{l}\text { Escala } \\
\text { de } \\
\text { Análise }\end{array}$ & $\begin{array}{l}\text { Unidade de } \\
\text { Análise }\end{array}$ & Temática \\
\hline RBG & $\begin{array}{l}\text { Alves, et } \\
\text { al. }\end{array}$ & 2007 & Prático & Integrado & $\begin{array}{l}\text { Local/ } \\
\text { Regional }\end{array}$ & Zona costeira & Dinâmica geoambiental \\
\hline Anpege & Amorim & 2016 & Prático & Compart. & Regional & $\begin{array}{l}\text { Região } \\
\text { costeira }\end{array}$ & $\begin{array}{c}\text { Mapeamento de } \\
\text { geossistema/paisagem }\end{array}$ \\
\hline $\begin{array}{l}\text { Soc. \& } \\
\text { Nat. }\end{array}$ & $\begin{array}{l}\text { Amorim, } \\
\text { Oliveira }\end{array}$ & 2008 & Prático & Integrado & Local & $\begin{array}{l}\text { Município de } \\
\text { região costeira }\end{array}$ & $\begin{array}{l}\text { Mapeamento de } \\
\text { unidades de paisagem e } \\
\text { análise geoambiental }\end{array}$ \\
\hline $\begin{array}{l}\text { Geografia } \\
\text { (Rio Claro) }\end{array}$ & $\begin{array}{l}\text { Cavalcanti, } \\
\text { et al. }\end{array}$ & 2010 & Teórico & Compart. & Regional & Messoregião & $\begin{array}{l}\text { Mapeamento de } \\
\text { geossistema }\end{array}$ \\
\hline Geosul & $\begin{array}{l}\text { Cavalcanti } \\
\text { e Corrêa }\end{array}$ & 2013 & Teórico & Compart. & $\mathrm{X}$ & $\mathrm{X}$ & $\begin{array}{l}\text { Hierarquização } \\
\text { espacial e funcional na } \\
\text { ecologia da paisagem }\end{array}$ \\
\hline $\begin{array}{l}\text { Geografia } \\
\text { (Londrina) }\end{array}$ & $\begin{array}{l}\text { Cavalcanti } \\
\text { e Corrêa }\end{array}$ & 2014 & Prático & Compart. & Local & $\begin{array}{l}\text { Unidade de } \\
\text { conservação }\end{array}$ & $\begin{array}{c}\text { Pluviosidade e } \\
\text { fenologia de planta }\end{array}$ \\
\hline $\begin{array}{l}\text { Soc. \& } \\
\text { Nat. }\end{array}$ & $\begin{array}{l}\text { Dias e } \\
\text { Oliveira }\end{array}$ & 2012 & Prático & Integrado & $\begin{array}{l}\text { Local/ } \\
\text { Regional }\end{array}$ & Zona costeira & Unidades de paisagem \\
\hline RBG & $\begin{array}{l}\text { Marques } \\
\text { Neto }\end{array}$ & 2016 & Prático & Compart. & $\begin{array}{l}\text { Local/ } \\
\text { Regional }\end{array}$ & $\begin{array}{l}\text { Unidade de } \\
\text { conservação }\end{array}$ & $\begin{array}{l}\text { Unidades de paisagem } \\
\text { e relações entre o } \\
\text { sistema } \\
\text { geomorfológico e os } \\
\text { geossistemas }\end{array}$ \\
\hline $\begin{array}{c}\text { Geografia } \\
\text { (Rio Claro) }\end{array}$ & $\begin{array}{c}\text { Marques } \\
\text { Neto, et al. }\end{array}$ & 2014 & Prático & Compart. & Regional & $\begin{array}{c}\text { Bacia } \\
\text { hidrográfica }\end{array}$ & $\begin{array}{l}\text { Mapeamento de } \\
\text { sistemas ambientais } \\
\text { físicos }\end{array}$ \\
\hline $\begin{array}{l}\text { Revista de } \\
\text { Geografia } \\
\text { (UFPE) }\end{array}$ & $\begin{array}{l}\text { Melo e } \\
\text { Guerra }\end{array}$ & 2013 & Prática & Compart. & Local & Assentamento & $\begin{array}{l}\text { Interrações sistema } \\
\text { geofísico }\end{array}$ \\
\hline $\begin{array}{l}\text { Geografia } \\
\text { (Rio Claro) }\end{array}$ & $\begin{array}{l}\text { Moretti e } \\
\text { Ferreira }\end{array}$ & 2011 & Prática & Integrada & Regional & Estado & $\begin{array}{l}\text { Regionalização } \\
\text { epidemiologica }\end{array}$ \\
\hline $\begin{array}{l}\text { Soc. \& } \\
\text { Nat. }\end{array}$ & $\begin{array}{l}\text { Neves, et } \\
\text { al. }\end{array}$ & 2014 & Teórico & Integrada & $\mathrm{X}$ & $\mathrm{X}$ & Análise do ambiente \\
\hline $\begin{array}{l}\text { Geografia } \\
\text { (UFPE) }\end{array}$ & $\begin{array}{l}\text { Neves, et } \\
\quad \text { al. }\end{array}$ & 2015 & Prático & Integrada & Local & $\begin{array}{l}\text { Setores da } \\
\text { cidade }\end{array}$ & $\begin{array}{c}\text { Degradação } \\
\text { socioambiental }\end{array}$ \\
\hline RBG & $\begin{array}{l}\text { Oliveira, et } \\
\text { al. }\end{array}$ & 2007 & Prática & Integrada & Regional & $\begin{array}{l}\text { Unidade de } \\
\text { conservação }\end{array}$ & $\begin{array}{l}\text { Unidades de paisagem } \\
\text { e Ecoturismo }\end{array}$ \\
\hline RBGF & $\begin{array}{l}\text { Oscar } \\
\text { Júnior }\end{array}$ & 2013 & Prático & Integrado & Regional & $\begin{array}{l}\text { Região } \\
\text { costeira }\end{array}$ & $\begin{array}{c}\text { Planejamento e gestão } \\
\text { ambiental }\end{array}$ \\
\hline $\mathrm{RBC}$ & $\begin{array}{l}\text { Paula e } \\
\text { Souza }\end{array}$ & 2010 & Prático & Compart. & Local & $\begin{array}{c}\text { Bacia } \\
\text { hidrográfica }\end{array}$ & $\begin{array}{l}\text { vulnerabilidade } \\
\text { ambiental por SIG }\end{array}$ \\
\hline $\begin{array}{l}\text { Geografia } \\
\text { (Rio Claro) }\end{array}$ & Reis Júnior & 2007 & Teórico & Integrado & $\mathrm{X}$ & $\mathrm{X}$ & Pensamento geográfico \\
\hline $\begin{array}{l}\text { Geografia } \\
\text { (UFPE) }\end{array}$ & $\begin{array}{l}\text { Ribeiro, et } \\
\text { al. }\end{array}$ & 2010 & Prático & Integrado & Local & $\begin{array}{c}\text { Bacia } \\
\text { hidrográfica }\end{array}$ & $\begin{array}{c}\text { Análise geoambiental } \\
\text { da paisagem, } \\
\text { geossistema }\end{array}$ \\
\hline $\begin{array}{l}\text { Geografia } \\
\text { (UFPE) }\end{array}$ & $\begin{array}{l}\text { Silva e } \\
\text { Corrêa }\end{array}$ & 2007 & Prático & Integrado & Local & $\begin{array}{c}\text { Bacia } \\
\text { hidrográfica }\end{array}$ & $\begin{array}{l}\text { Relação uso da terra e } \\
\text { geossistema }\end{array}$ \\
\hline Mercator & Soares & 2006 & Prático & Integrado & Local & $\begin{array}{c}\text { Bacia } \\
\text { hidrográfica }\end{array}$ & $\begin{array}{l}\text { Classificação da } \\
\text { paisagem por meio do } \\
\text { relevo e uso }\end{array}$ \\
\hline RBGF & Souza & 2014 & Prático & Integrado & $\begin{array}{l}\text { Local/ } \\
\text { Regional }\end{array}$ & $\begin{array}{c}\text { Bacia } \\
\text { hidrográfica }\end{array}$ & $\begin{array}{l}\text { Transformação das } \\
\text { paisagem pelo uso }\end{array}$ \\
\hline Mercator & $\begin{array}{l}\text { Troppmair } \\
\text { e Galina }\end{array}$ & 2006 & Teórico & Integrada & $X$ & $X$ & $\begin{array}{l}\text { Evolução da visão } \\
\text { sistêmica em Geografia }\end{array}$ \\
\hline
\end{tabular}

Fonte: Autores, 2017. 


\section{CONCLUSÕES}

Este estudo permitiu o vislumbramento da versatilidade do conceito de paisagem, permitindo-se pensar em novas bases conceituais e temáticas ao desenvolvimento da Geografia Física Integradora, sendo o seu conhecimento importante à manutenção da sociobiodiversidade e do patrimônio natural brasileiro.

Aponta-se que, ao se estudar a integração trazida pelo debate paisagístico analisado, pode-se também entender as múltiplas facetas da estrutura, funcionamento, dinâmica e evolução dos complexos ambientais. Dessa forma, trabalhar com temáticas relacionadas ao uso e cobertura da terra tem possibilitado entender mudanças temporais e espaciais da paisagem, sobretudo pela relação entre os inputs e outputs de matéria e energia do sistema, sendo a paisagem uma herança dessas relações.

Assim, ao se relacionar sociedade $\leftrightarrow$ natureza na análise paisagística, permite-se entende-la enquanto conceito integrador da Geografia, fomentando a discussão sobre o planejamento e a gestão ambiental e territorial em distintas escalas analíticas. Nesse âmbito, observa-se a predominância da escala local e local/regional com enfoque na transformação e fragmentação da paisagem. Também destaca-se a bacia hidrográfica, que tem sido frequentemente vista como palco de análise por ser uma unidade básica de diversas políticas públicas voltadas ao planejamento e à gestão ambiental.

Por fim, indica-se a importância do geossistema e do seu potencial teórico-metodológico para a integração dos componentes paisagísticos e da relação sociedade $\leftrightarrow$ natureza. A partir do geossistema, a paisagem tem apresentado um enfoque ainda mais prático, bem como evidenciado subsídios ao diagnóstico e prognóstico ambiental e territorial. Apesar dessa aproximação, deixa-se claro que o geossistema não é a paisagem em sua totalidade, uma vez que há uma maior abrangência no conceito de paisagem (real e abstrato) e que estes conceitos são criados para finalidades particulares.

Por fim, pode-se dizer que a paisagem e o geossistema caminham paralelamente e são, em conjunto, conceitos em construção, importantes ao debate da Geografia Física Integradora. Assim, olhar para o passado (próximo e distante) possibilita o resgate das estruturas da análise geográfica integrada, dinâmica e sistêmica, com a qual pode-se compreender os contextos atuais e futuros (VENTURI, 2014) da pesquisa paisagística que relaciona sociedade $\leftrightarrow$ natureza enquanto um par dialético.

\section{AGRADECIMENTOS}

Ao apoio da Fundação de Amparo à Pesquisa do Estado de São Paulo (FAPESP) através do financiamento da pesquisa intitulada "Caminhos e Descaminhos da Aplicação do Conceito de Geossistema: análise da produção brasileira e as influências de Georges Bertrand" (Processo n. 201506558-9).

Ao apoio e orientação do Professor Doutor Messias Modesto dos Passos (FCT/UNESP) e da estrutura do Grupo de Pesquisa Gestão Ambiental e Dinâmica Socioespacial (GADIS - FCT/UNESP), bem como do debate constante com os amigos do laboratório.

Ao apoio na correção do texto e na tradução do resumo pela Maximus Serviços Linguísticos - MSL, com destaque à figura do tradutor Natanael Ferreira França Rocha.

\section{BIBLIOGRAFIA}

AB'SABER, A. N. Um Conceito de Geomorfologia a Serviço das Pesquisas sobre o Quaternário. Geomorfologia, n. 18, p.1-23, IGEOG-USP, 1969.

AB'SABER, A. N. Os domínios de natureza no Brasil: potencialidades paisagísticas. 3. ed. Ateliê Editorial, 2003. 151p.

ALVARENGA, L. Bibliometria e arqueologia do saber de Michel Foucault - traços de identidade teóricometodológica. Ciência da Informação, v. 27, n. 3, p. 1-9, 1998.

ALVES, N. M. S.; FONTES, A. L.; SILVA, D. B.; ALMEIDA, J. A. P. Dinâmica geoambiental, processos morfodinâmicos e uso das terras em Brejo Grande, Baixo São Francisco - Sergipe. Revista Brasileira de Geomorfologia, v.8, n.2, p.11-21, 2007

AMORIM, R. R. A representação de mapas de paisagens na escala regional: o exemplo da Região Costa do Descobrimento (Bahia). Revista da Anpege V.12, n.17. p.257-292, jan-jul. 2016. 
AMORIM, R. R.; OLIVEIRA, R. C. As unidades de paisagem como uma categoria de análise geográfica: o exemplo do município de São Vicente-SP. Sociedade \& Natureza, Uberlândia, ano 20, n. 2, p. 177-198, 2008.

BEROUTCHACHVILI, N.; BERTRAND, G. Le Geosystéme ou Systéme Territorial Naturel. Revue Géographique des Pyrinées et du Ouest. Toulose. v. 49, n. 2, p. 167-180. 1978.

BARRETTO, A. G. O. P.; BARROS, M. G. E.; SPAROVEK, G. Bibliometria, história e geografia da pesquisa brasileira em erosão acelerada do solo. Revista Brasileira de Ciências do Solo, n. 32, p. 24432460. 2008.

BERTRAND, C. Paysage et géographie physique globale. Esquisse méthodologique. Revue Géographique des Pyrénées et du Sud-ouest, Toulouse, v. 39, n. 3, p. 249-272. 1968.

BRASIL. Decreto $\mathrm{n}^{\circ}$ 4.297, de julho de 2002. O Zoneamento Ecológico-Econômico do Brasil - ZEE, como instrumento da Política Nacional do Meio Ambiente. Brasília, 2002. Disponível em: http://www.planalto.gov.br/ccivil_03/decreto/2002/d4297.htm. Acesso em: 02 fev. de 2017.

CAVAlCANTI, L. C. S. I; CORRÊA, A. C. B. Da Descrição de Áreas às Sínteses Naturalistas: uma abordagem historiográfica sobre a ideia de 'áreas naturais'. Espaço \& Geografia, v.17, n. 2, p. 377-422. 2014.

CAVALCANTI, L. C. S. I; CORRÊA, A. C. B. Problemas de hierarquização espacial e funcional na ecologia da paisagem: uma avaliação a partir da abordagem geossistêmica. Geosul, Florianópolis, v. 28, n. 55, p. 143 162, jan./jun. 2013.

CAVALCANTI, L. C. S.; CORREA, A. C. B.; ARAÚJO FILHO, J. C. Fundamentos para o mapeamento de geossistemas: uma atualização conceitual. Geografia, Rio Claro, v. 35, n. 3, p. 539-551, set./dez. 2010.

CAVALCANTI, L. C. S.I; CORRÊA, A. C. B. Pluviosidade no Parque Nacional do Catimbau (Pernambuco): seus Condicionantes e seus Efeitos sobre a Paisagem. Geografia (Londrina) v. 23, n. 2. p. 133-156, jul/dez, 2014.

CAVALHEIRO, F.; PRESOTTO, A; ROCHA Y. T. Planejamento e projeto paisagístico e a identificação de unidades de paisagem: o caso da Lagoa Seca do bairro Jardim América, Rio Claro (SP). Geousp, n. 13, p. 161-167, 2003.

CHRISTOFOLETTI, A. Análise de Sistemas em Geografia. São Paulo: Hucitec/Edusp: 1979. 105p.

DIAS, R. L.; OLIVEIRA, R. C. Análise das paisagens do litoral sul do estado de São Paulo. Sociedade \& Natureza, Uberlândia, ano 24 n. 3, p. 505-518, set/dez. 2012.

DOYLE, M. N.; JULIAN, J. P. The most cited works in Geomorphology. Geomorphology, n. 72, p. 238-249. 2005.

FROLOVA, M. Desde el concepto de paisaje a la Teoría del geosistema en la Geografía rusa: ¿hacia una aproximación global del medio ambiente? Ería, n. 70, p. 225-235. 2006.

MARANHÃO, R. A. Análise da Produção Científica em Geografia Médica e da Saúde: algumas reflexões. Caminhos de Geografia, Uberlândia v. 15, n. 49 Mar/2014 p. 41-49. 2014.

MARQUES NETO, R. Geomorfologia e geossistemas: influências do relevo na definição de unidades de paisagem no maciço alcalino do Itatiaia (MG/RJ). Revista Brasileira de Geomorfologia (Online), São Paulo, v.17, n.4, (Out-Dez) p.729-742. 2016.

MARQUES NETO, R.; PEREZ FILHO, A.; OLIVEIRA, T. A. Geossistemas na Bacia do Rio Verde (MG): proposta de mapeamento de sistemas ambientais físicos em escala regional. Geografia, Rio Claro, v. 39, $\mathrm{n}$. 2, p. 321-336. 2014.

MARTINELLI, M. Cartografia Ambiental: uma cartografia diferente?. Revista do Departamento de Geografia (RDG), n. 7, p. 61-80. 1994.

MARTINELLI, M. E PEDROTTI, F. A Cartografia das Unidades de Paisagem: questões metodológicas. Revista do Departamento de Geografia (RDG), n. 14, p. 39-46. 2001.

MELO, A. C.; GUERRA, H. O. C. Descrição do Sistema Geofísico do Assentamento Patativa do Assaré Patos/PB. Revista de Geografia (UFPE) v. 30, n. 1, 2013. 
MONTEIRO, C. A. F. A Geografia no Brasil (1934-1977): avaliação e tendências. Universidade de São Paulo. Série Teses e Monografias n. 37. Instituto de Geografia, São Paulo. 1980.158p.

MONTEIRO, C. A. F. The Environmental quality in the Ribeirão Preto Region, SP - an attempt. Commision on Environmental Problems, São Paulo, UGI, 1982.30p.

MONTEIRO, C. A. F. Geossistemas: a história de uma procura. São Paulo: Contexto, 2000.127p.

MORETTI, A. I.; FERREIRA, M. C. Dinâmica espacial e regionalização da leishmaniose tegumentar americana no estado de São Paulo. Geografia, Rio Claro, v. 36, n. 3, p. 453-468, set./dez. 2011.

NEVES, C. E.; MACHADO, G. Geografia e Ambiente: trajetórias e tendências das pesquisas geossistêmicas no estado de São Paulo, Brasil. Confins [online]. n. 30, p. s/n, 2017. DOI: http://dx.doi.org/10.4000/confins.11716

NEVES, C. E. MACHADO, G. HIRATA, C. A.; STIPP, N. A. F. A importância dos geossistemas na pesquisa geográfica: uma análise a partir da correlação com o ecossistema. Sociedade \& Natureza, Uberlândia, ano 26, n. 2, p. 271-285. 2014. DOI: http://dx.doi.org/10.1590/1982-451320140206

NEVES, S. M.; BARBOSA, A. M. F.; SOUZA, R. M. Análise geoambiental do município de Uruçuí - PI. Revista de Geografia, UFPE. v.32, n.1, p.151-166. 2015.

NUCCI, J. C. A paisagem e as paisagens. Paisagens (USP), São Paulo, v. 2, n.3, p. 13-14. 1998.

OLIVEIRA, S. N.; CARVAlHO JUNIOR, O. A.; MARTINS, E. S.; SILVA, T. M. GOMES, R. A. T. Identificação de unidades de paisagem e sua implicação para o ecoturismo no Parque Nacional da Serra dos Órgãos, Rio de Janeiro. Revista Brasileira de Geomorfologia, v. 8, n. 1, p. 87-107. 2007.

ORTIGOZA, S. A. G. POLTRONIÉRI, L. C.; MACHADO, L. M. C. P. Pós-graduação: metodologia para reestruturação de linhas de pesquisa. Revista da ANPEGE, v. 7, n. 8, p. 143-154, ago./dez. 2011.

OSCAR JÚNIOR, A. C. S. A Paisagem da Baixada Fluminense: uma análise na perspectiva geoecológica. Revista Brasileira de Geografia Física v. 06, n. 02, p. 195-210. 2013.

PASSOS, M. M. Biogeografia e Paisagem. Presidente Prudente: UNESP, 2003.264p.

PASSOS, M. M. Paisagem e Meio Ambiente (Noroeste do Paraná). Maringá: Eduem, 2013. 220p.

PAULA, E. M. S.; SOUZA, M. J. N. Sistemas de informações geográficas na análise da vulnerabilidade ambiental da Bacia do Rio Ceará-CE. Revista Brasileira de Cartografia, n. 63/4, p. 515-525. 2010.

REIS JÚNIOR, D. F. C. História de um pensamento geográfico: Georges Bertrand. Geografia, Rio Claro, v. 32, n. 2, p. 363-390, mai./ago. 2007.

RIBEIRO, S. C.; LIMA, F. J.; MARÇAL, M. S. O enquadramento paisagístico como contribuição aos estudos da sub-bacia do Rio Salgado/CE: do domínio morfoestrutural aos geossistemas. Revista de Geografia. Recife: UFPE - DCG/NAPA, especial VIII SINAGEO, n. 2, p. 121-135, Set. 2010.

ROSS, J. L. S. Análises e sínteses na abordagem geográfica da pesquisa para o planejamento ambiental, Revista do Departamento de Geografia, São Paulo, FFLCH/USP, n. 9, p. 65-75. 1995.

SALINAS, E. Y; REMOND, R. El Enfoque Integrador del Paisaje en los Estudios Territoriales: Experiencias Prácticas, En: GARROCHO, C.; BUZAI, Y. G. (Org.) Geografía Aplicada en Iberoamérica: avances, retos y perspectivas, México, 2015. p. 503-542.

SILVA, F. L. M.; CORRÊA, A. C. B. Relações entre geossistemas e usos da terra em microbacia hidrográfica semi-árida: o caso do Riacho Gravatá/ Pesqueira - PE. Revista de Geografia. Recife: UFPE - DCG/NAPA, v. 24, no 1, jan/abr. 2007

SNYTKO, V. A.; SEMENOV, Y, M. The study of geosystem structure, development and functioning in Siberia. Methodology of landscape research, Dissertations Commission of Cultural Landscape. Commission of Cultural Landscape of Polish Geographical Society, Sosnowiec, 141-150, n. 9, 2008.

SOARES, F. M. As paisagens da Bacia Hidrográfica do Rio Curu: exploração de um campo de estudo da Geografia Física integrada. Mercator, ano 05, número 09, p. 95-104, 2006.

SOUZA, J. C. O. Análise geossistemica na bacia hidrográfica do Rio São Miguel, Alagoas: estudo e interpretação de paisagens hidrogeomorfológicas. Revista Brasileira de Geografia Física, v.07, n.05 (Número Especial-VIWMCRHPE), p. 880-890. 2014. 
SOCHAVA, V. B. Uma Introdução à Ciência dos Geossistema. Novosibirsk: Nauka, 1978. 318p. [em russo]

SUERTEGARAY, D. M. A.; MORETTI, E. C. Considerações sobre o eixo temático Natureza no contexto dos Encontros Nacionais de Geógrafos (Brasil) 2008-2012. Terra Livre, ano 30, v. 2, n. 42, p. 83-100, 2014.

TRICART, J. Paisagem e ecologia. Inter-Facies: escritos e documentos. São José do Rio Preto: Ed. UNESP, 1982. 55p.

TROLL, C. Landscape Ecology (Geoecology) and Biogeocenology. Geoforum, nº 8, 43-46. 1971.

TROPPMAIR, H. Ecossistemas e geossistemas do estado de São Paulo. Boletim de Geografia Teorética. Rio Claro. v.13, n.25, p. 27-36. 1983.

TROPPMAIR, H.; GALINA. M. H. Geossistemas. Mercator, v. 05, n 10, p. 80-89. 2006.

VENTURI, L.A.B. A Geografia e o Estudo do Ambiente. Ciência e Natura, v. 36, p. 246-256. 2014.

VITTE, A. C. O desenvolvimento do conceito de paisagem e a sua inserção na Geografia Física. Mercator, v 6, n. 11, p. 71-78, 2007.

VITTE, A. C. A Geografia Física no Brasil: Um panorama quantitativo a partir de periódicos nacionais (19282006). Revista da ANPEGE, n. 4, p. 47-60. 2008. 